\title{
DETERMINING THE RELIABILITY OF CLINCHER COOLERS
}

\author{
Teodor VASIU, Adina BUDIUL BERGHIAN \\ University POLITEHNICA Timişoara, Engineering faculty of HUNEDOARA, Romania \\ e-mail: teodor.vasiu@ fih.upt.ro
}

\begin{abstract}
For any industrial entity that is put into operation, the problem of maintaining its functioning if possible, with corresponding technical and technological parameters without failure is an important issue. This is provided by the study of the technical availability of that entity. Technical availability consists of two directions, namely: increasing the reliability, i.e. the duration of the good functioning, under operating conditions and for a well-established period and ensuring adequate maintenance. The two directions should be studied together in order to find solutions to increase the service life while reducing maintenance requests. In the present case, for the clinker coolers, only real reliability has been studied with the aim of finding practical solutions for increasing the service life. Achieving the proposed objective required the observation of the operation / failure of such a machine over nine months and the statistical processing of the information obtained.
\end{abstract}

KEYWORDS: cement industry, clinker, cooler, reliability

\section{Introduction}

In Romania, in 2004, the sale of cement was about 5 million tons, which corresponded to a value of approximately EUR 250 million. In 2005, the cement market was valued at 300 million-euro, accounting for 5-6\% of the total construction market. In 2010, the cement market was estimated at 500 million euro, and in 2014 the local cement market was estimated at around 500-600 million euro [1].

Cement production begins in the limestone quarry, excavating limestone and clay. Then they are crushed into pieces by the size of a coin. These raw materials, together with a material that has iron intake, are homogenized in a powder called "raw meal". The raw meal is heated to a temperature of $1,450{ }^{\circ} \mathrm{C}$. The high temperature turns the flour into a new material, called clinker [1].

The clinker is suddenly cooled, and then ground together with gypsum in a fine powder. This is Portland cement. To produce different types of cement, slag and/or ash of thermal power (material resulting from the combustion of coal or other mineral materials) is added. Therefore, clinker coolers are the main machinery in cement making technology, and the study of their faultless operation is an important objective.

On the other hand, firing and cooling of the clinker is the most important part of the cement manufacturing process, which raises key ecological problems in terms of nitrogen and sulphur oxides and dust emissions.

This brief introduction shows how important is the study of cement manufacturing technology in general, and clinker equipment in particular.

\section{Collection and processing of experimental data}

In order to accomplish the proposed goal, the operation / failure of a clinker cooler was monitored for nine months. In [2] recommendations on observation duration are made. Good running and maintenance times were recorded on special papers.

Because we are concerned only with reliability, good running times have been considered and introduced into the Weibul++9 specialized software [3]. The good operating times entered in the program are shown in Figure 1.

The chosen software has the possibility of an analysis that provides the optimal distribution law for each case, i.e. the mathematical law with the maximum correlation coefficient between the experimental and the theoretical data.

For reliability, good running times respect logistic law (Fig. 2) with a correlation coefficient Rho $=0.986962$. The parameters of this law are: average $\mu$ $=705.583338$ hours and the location parameter (standard deviation) $\sigma=12.08021$ hours (Fig. 1). 


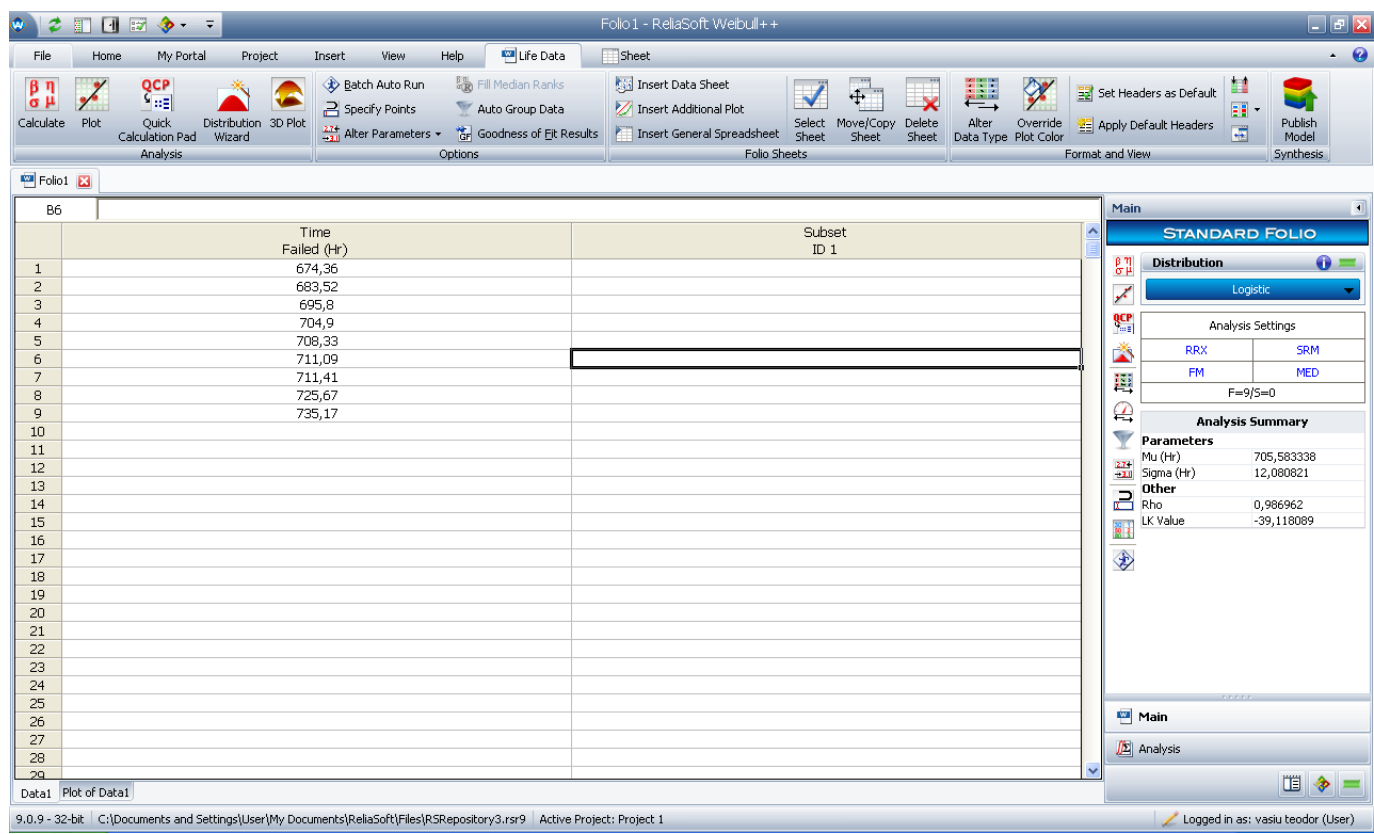

Fig. 1. Good running times

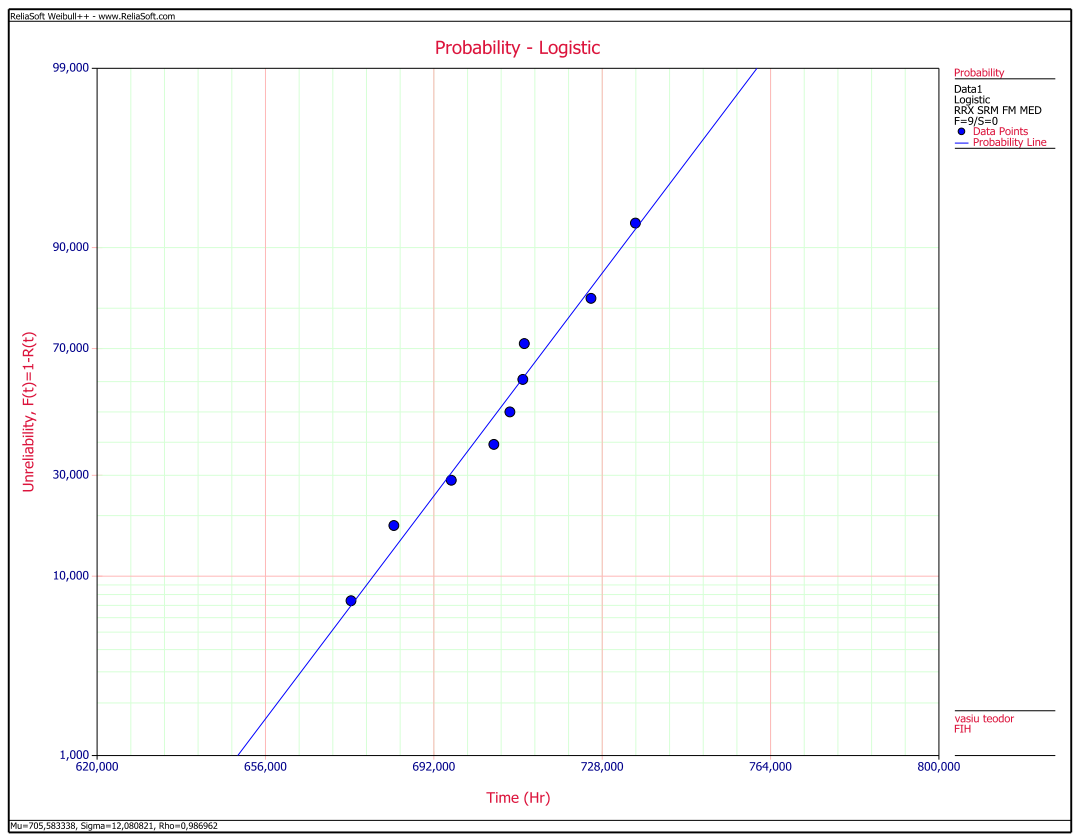

Fig. 2. Probabilistic diagram of the logistics function

Because the logistics law is not one that often appears in the reliability and maintenance studies, it is considered necessary to present this law. Logistics distribution has been used to model prototype operations but has also been useful in shaping the normal life of industrial entities. The form of logistics distribution and normal distribution are very similar. There are opinions that claim that the logistics distribution is inappropriate for lifetime modelling because the left limit of the distribution extends to $-\infty$. This could theoretically lead to negative operating times until failure. However, provided that the distribution in question has a relatively large average and a relatively small location parameter, the problem of negative times should not disturb.

The probability density of the logistic distribution is [4]: 


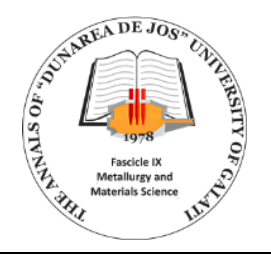

THE ANNALS OF "DUNAREA DE JOS" UNIVERSITY OF GALATI

FASCICLE IX. METALLURGY AND MATERIALS SCIENCE

No. 3 - 2018, ISSN 2668-4748; e-ISSN 2668-4756

Article DOI: $\underline{\text { https://doi.org/10.35219/mms.2018.3.08 }}$

$$
\begin{gathered}
f(t)=\frac{e^{z}}{\sigma\left(1+e^{z}\right)^{2}} \\
z=\frac{t-\mu}{\sigma} \\
-\infty<t<\infty, \quad-\infty<\mu<\infty, \sigma>0
\end{gathered}
$$

where $\mathrm{t}[\mathrm{Hr}]$ is the time of proper functioning.

\section{Interpretation of the obtained results}

There are not general rules to interpret statistical data, so everyone's experience is important $[5,9]$.

Figure 3 shows that the cooler's reliability is kept close to 1 for about 660 hours. This time may be a guarantee period for maintenance work; that means, it is incredible that any defect will occur within 660 hours.
This can also be seen in Figure 4 where the probability of failure (non-reliability) is close to zero, 660 hours after the cooler is commissioned.

The graph (Figure 5) of the logistic distribution probability density supports the assertion that the shape of logistic distributions and Gauss are similar.

The failure rate (Figure 6) of the cooler is low for about 660 hours, which is expected in the light of the developments in Figures 3 and 4 and will soon increase.

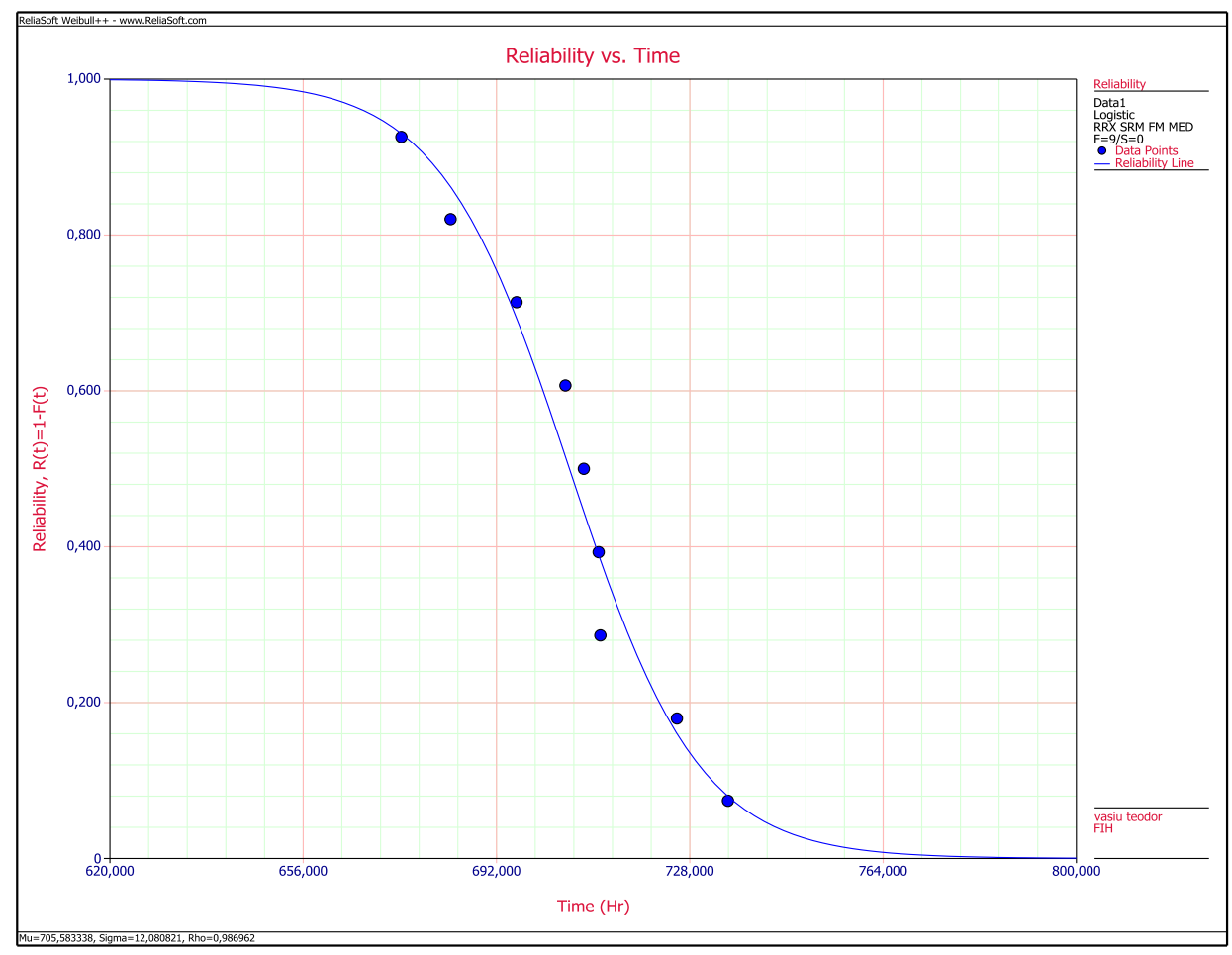

Fig. 3. Reliability versus time 


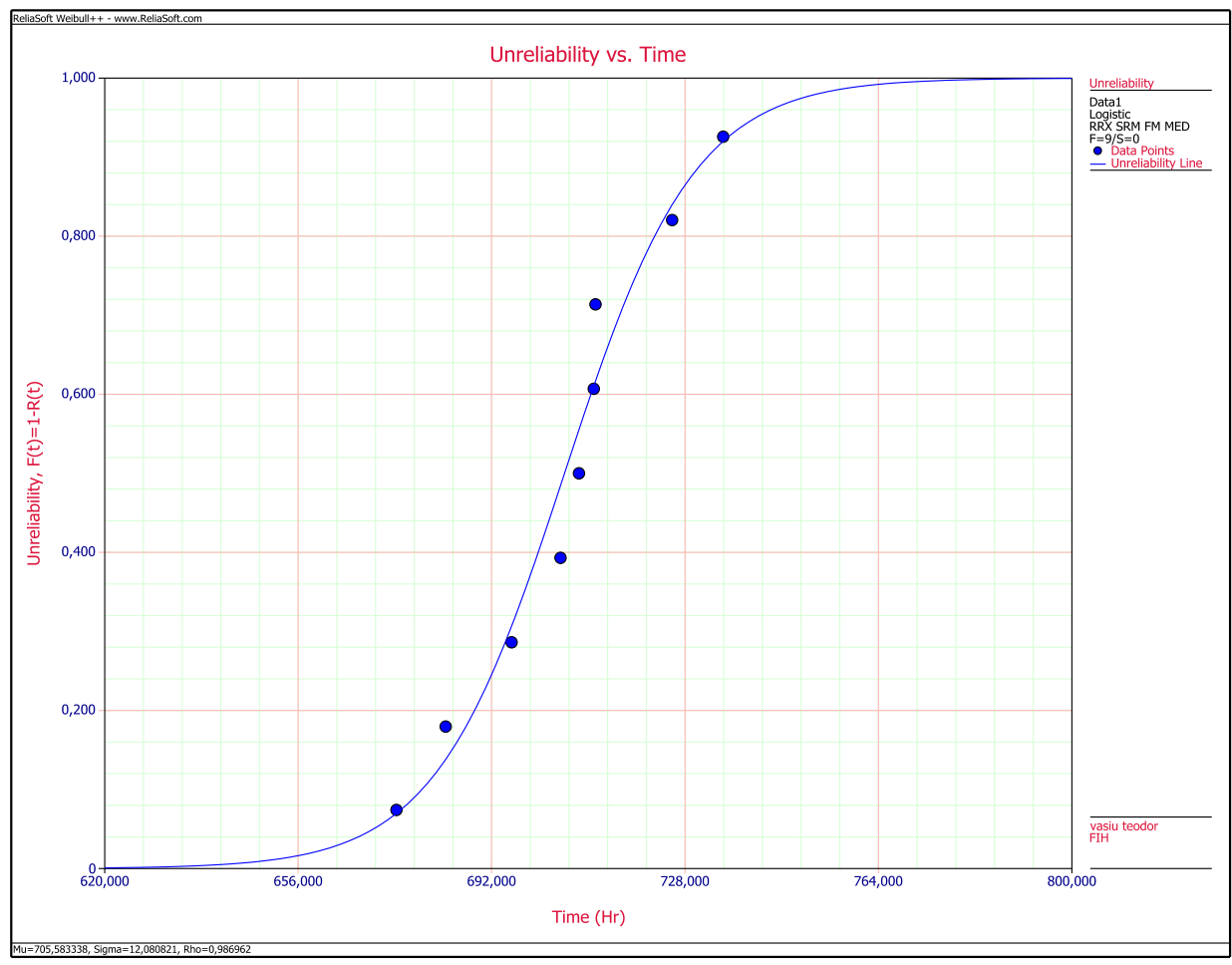

Fig. 4. Non-reliability versus time

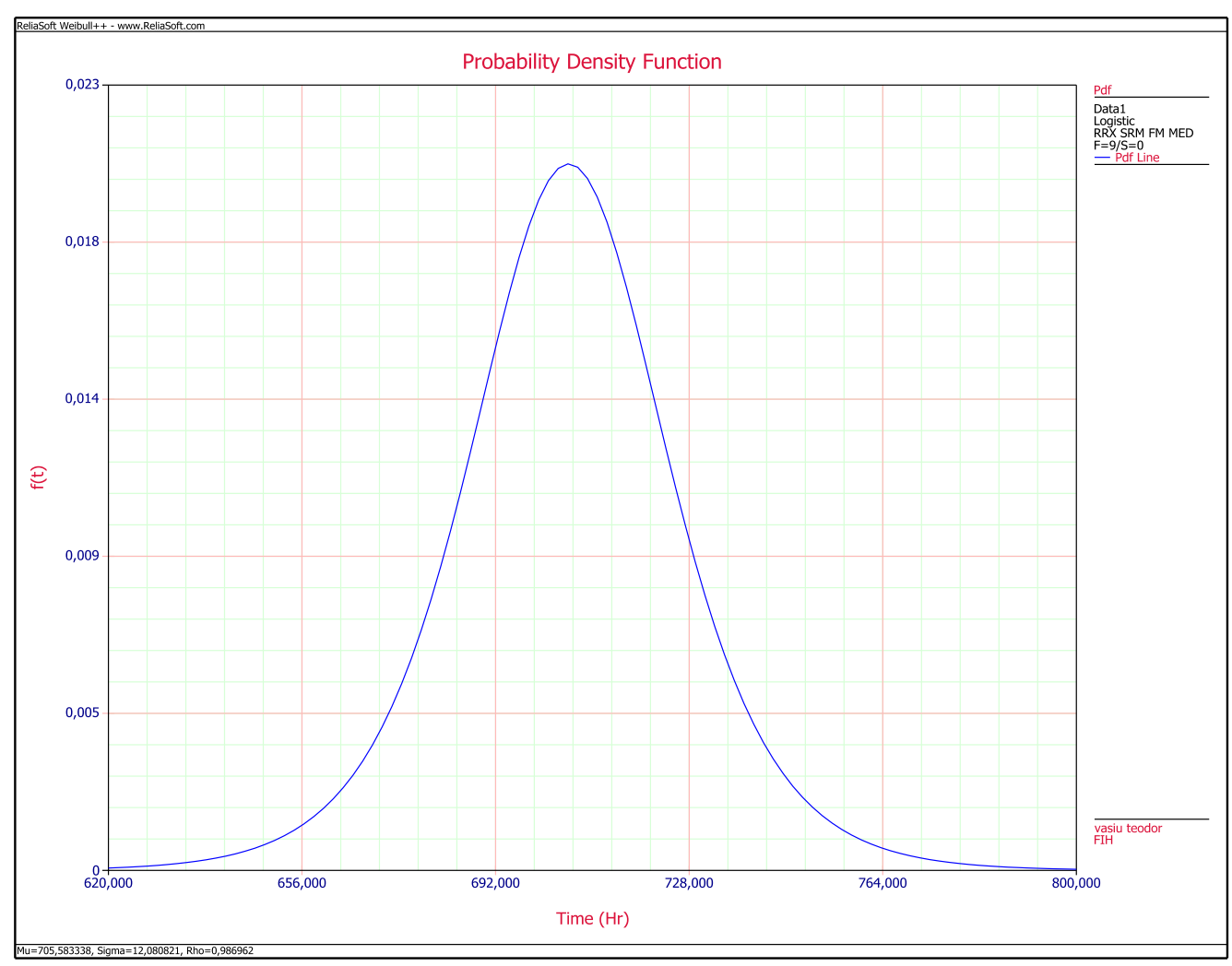

Fig. 5. Probability density of logistics distribution 


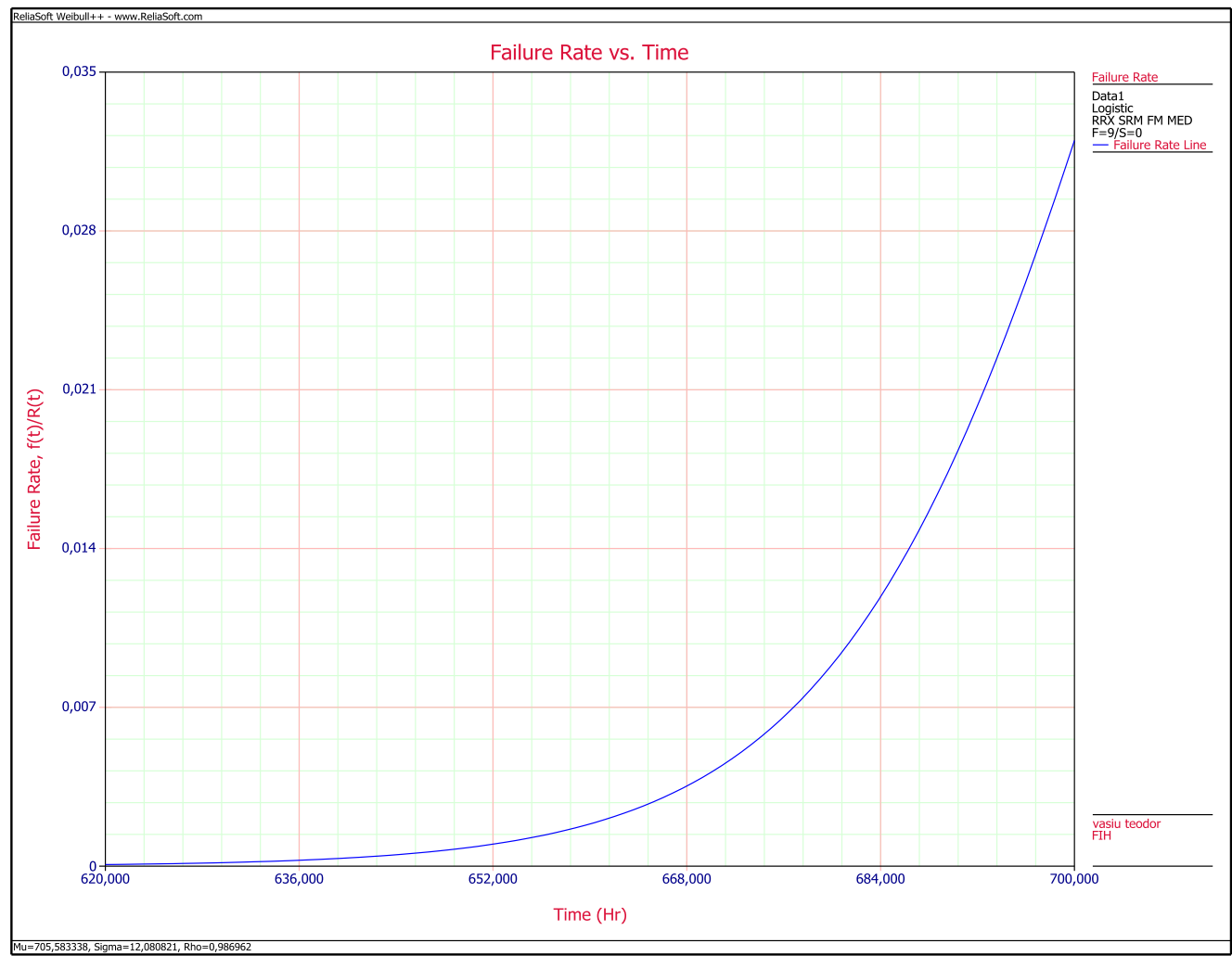

Fig. 6. Failure rate versus time

\section{LIKELIHOOD FUNCTION (Lk) SURFACE}

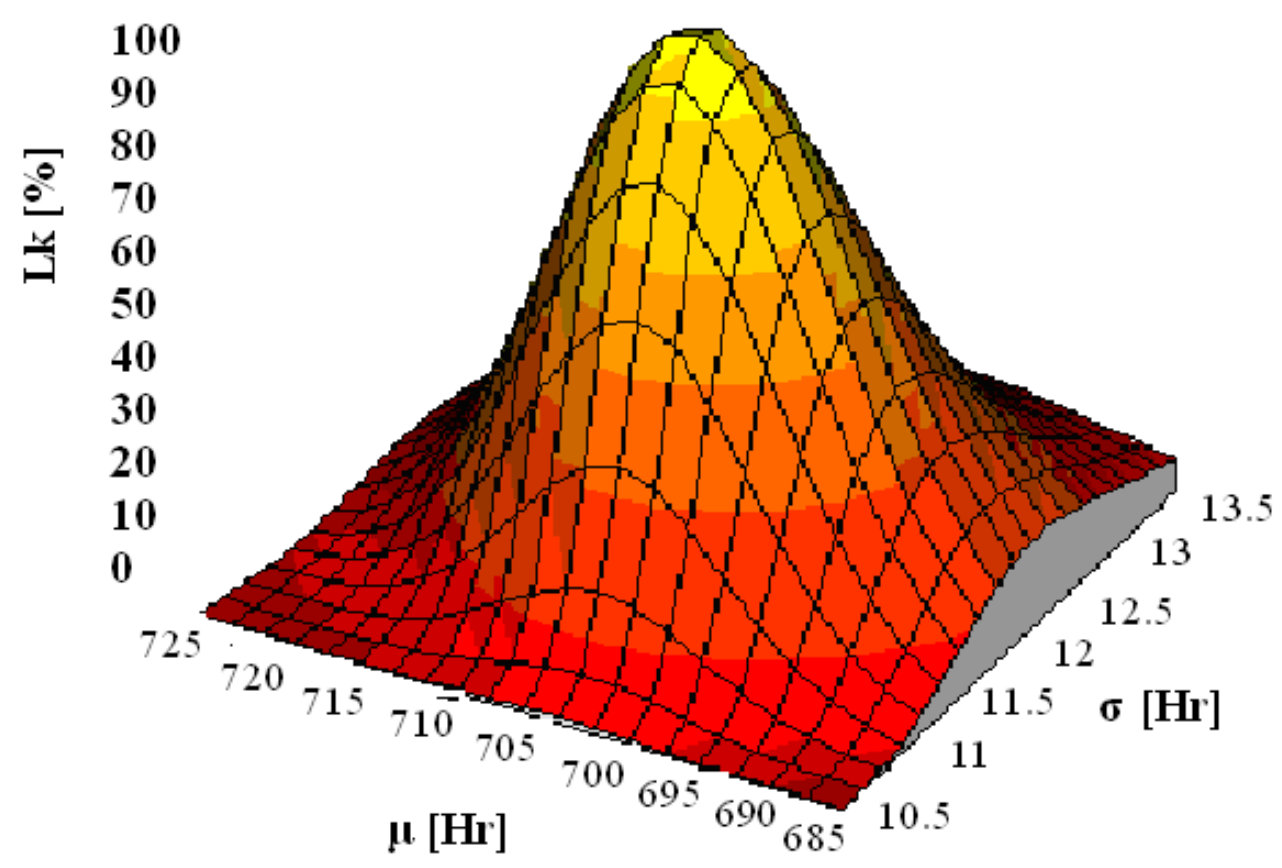

Fig. 7. Likelihood function of maximum verosimilitude 


\section{THE ANNALS OF "DUNAREA DE JOS” UNIVERSITY OF GALATI \\ FASCICLE IX. METALLURGY AND MATERIALS SCIENCE \\ No. 3 - 2018, ISSN 2668-4748; e-ISSN 2668-4756 \\ Article DOI: https://doi.org/10.35219/mms.2018.3.08}

The maximum verosimility function Lk (Fig. 7) shows that the values determined for the logistic law parameters are most probable, i.e. the pair of values $\mu$ $=705,583338$ hours and $\sigma=12,08021$ hours determines a maximum of the Likelihood function.

In statistics, a Likelihood function (often simply a likelihood) is a function of the parameter of a statistical model given data [10]. Likelihood functions play a key role in statistical inference. In informal contexts, "likelihood" is often used as a synonym for "probability". In statistics, the two terms have different meanings. Probability is used to describe the plausibility of some data, given a value for the parameter. Likelihood is used to describe the plausibility of a value for the parameter, given some data.

In this case, the Likelihood function has the form:

$$
\mathbf{L k}=\prod_{\mathbf{i}=1}^{9} f\left(\mathbf{t}_{\mathbf{i}}, \boldsymbol{\mu}, \boldsymbol{\sigma}\right)
$$

where $t_{i}, i=1,2, \ldots, 9$ are the values of the good functioning times in figure 1 , and $f$ is given by the relation (1).

The expression (2) can be used both to determine the parameters $\mu$ and $\sigma$, imposing the maximum condition for $\mathrm{Lk}$, and to check if the parameters obtained by other paths maximize the function Lk. This time, the second option was preferred.

\section{Conclusion}

The 660-hour time, determined by statistical calculations of experimental data, is an important value in the life of the cooler. During this time the reliability is maximum and the failure rate minimum. The technical-organizational actions (procedures, infrastructure, adequate qualification of maintenance and exploitation personnel, etc.) should be directed towards increasing this time. The final scope is to keep the cooler in operation for as long as possible so that the technological flow of cement production is not disturbed.

\section{References}

[1]. ***, https://ro.wikipedia.org/wiki/Ciment.

[2]. Baron T., et al., Calitate şi fiabilitate - manual practic, [Quality and Reliability - Practical Manual], vol. 1 and 2, Editura Tehnică, București, 1988.

[3]. ***, ReliaSoft Weibull++9 software.

[4]. Mihoc Gh., Muja A., Diatcu E., Bazele matematice ale teoriei fiabilităţii [Mathematical bases of reliability theory], Editura Dacia, Cluj-Napoca, 1976.

[5]. Vasiu T., Budiul Berghian A., Reliability of clincher burners from cement industry, Annals of Faculty of Engineering Hunedoara - International Journal of Engineering, Tome XVI, Fascicle 3 [August], ISSN 1584-2673, 2018.

[6]. Vasiu T., Fiabilitatea sistemelor electromecanice [Reliability of electromechanical systems], Editura Bibliofor, Deva, 2000.

[7]. Vasiu T., Budiul Berghian A., Reliability and maintainability of a shear for cutting metallurgical products, Metalurgia International, nr. 8, p. 5-11, 2008

[8]. Vasiu T., Practical reliability analysis method for repairable entities, Acta Universitatis Cibiniensis, vol. LIV, Techical series, Sibiu, p. 38-42, 2007.

[9]. Vasiu T., Budiul Berghian A., Statistical Procesing of Results for the Predictive Maintenance of an Industrial Fan, The $5^{\text {th }}$ International Sympozium KOD 2008, Novi Sad, Serbia, p. 287290, 15-16 April 2008.

[10]. ***, https://en.wikipedia.org/wiki/Likelihood_function. 